\title{
Effectiveness of an Ayurvedic Treatment Protocol in Knee Ligament Injuries - An Observatory Report
}

\author{
K.M. Pratap Shankar ${ }^{1}$, P. P. Nair², G. Sureshkumar ${ }^{3}$, G.K. Swamy ${ }^{4}$ \\ 1,2 Research Office (Ay), NARIP, Cheruthurthy, CCRAS, Ministry of AYUSH, Government of India, New Delhi, India \\ 3 Statistician \\ ${ }^{4}$ Director, NARIP, Cheruthurthy, CCRAS, Ministry of AYUSH, Govt of India, 679531.
}

\section{CORRESPONDING AUTHOR:}

K.M. Pratap Shankar

Research Office (Ay), NARIP

Cheruthurthy, CCRAS

Ministry of AYUSH, Government of India

679531 New Delhi, India

E-mail: kmpvarma@gmail.com

DOI:

10.32098/mltj.03.2020.16

LEVEL OF EVIDENCE: 4

\section{SUMMARY}

Objective. We aimed to document the effectiveness of an Ayurvedic treatment protocol in patients with knee ligament injuries.

Methods. We observed 20 patients with knee ligament injuries ranging from partial to complex meniscal/ligamentous pathological states who underwent an Ayurvedic treatment protocol. Knee Outcome survey (KOOS) and International Knee Documentation Committee (IKDC) scores were assessed as baseline figures along with supportive radiological reports if available such as an MRI and the same scores were used to assess the effectiveness of the Ayurvedic treatment protocol. Person centered stage wise administration of Ayurvedic medicaments and external therapies were carried out for the concerned patients. The outcome measures of change in KOOS and IKDC scores were analyzed pre-treatment [a1], post-treatment [a2] and after a follow-up [a3] of 3 months. Data analysis was carried out using Statistical Package for Social Sciences (SPSS). The ordinal data was subjected to Friedman's test. Post Hoc comparisons were carried out using Wilcoxon test (with Bonferroni correction). Results with p-value $<0.01$ were considered significant. Results. There were statistically significant differences in KOOS and IKDC scores between a1 and a2; \& a1 \& a3. When analyzed between a2 \& a3 in the prescribed parameters, results were statistically insignificant. KOOS-Overall scores with Friedman's test between a1, a2 and a3 were $\chi^{2}(2)=28.737, p=0.000<0.01$. Post hoc analysis with Wilcoxon signed-rank tests (at Bonferroni-adjusted significance level) between a1 \& a2 gave results $Z=-3.921, p$ $=0.000<0.017$ and between $\mathrm{a} 1 \& \mathrm{a} 3$ it was $\mathrm{Z}=-3.771, \mathrm{p}=0.000<0.017$. Between a2 \& a3 the result was $Z=0.000, p=1.000>0.017$. IKDC score withFriedman's test between a1, a2 \& a3 were $\chi^{2}(2)=32.430, p=0.000<0.01$. Post hoc analysis with Wilcoxon signedrank tests, between a1 \& a2 was $Z=-3.920, p=0.000<0.017$ and between a1 \& a3 was $\mathrm{Z}=-3.922, \mathrm{p}=0.000<0.017)$. The analysis between $\mathrm{a} 2 \&$ a3 gave result $\mathrm{Z}=-2.234, \mathrm{p}=$ $0.025>0.017)$. A variable in knee joint rehabilitation viz. the body mass index (BMI) of the patients did not seem to influence the results. The treatment was found to be comparatively more effective in females and in patients who engaged in moderate labour as well as who led a sedentary lifestyle. Elderly population though of less number in the study, experienced improved joint stability and relief in symptoms statistically as well as clinically. Conclusions. The preliminary analysis of this observatory report indicates that suggested Ayurvedic treatment protocol is effective in knee ligament injuries, wherein it improves joint stability, reduces the symptoms of pain, swelling, stiffness and rehabilitates the individual towards his daily activities of strenuous/non strenuous origin. The effectiveness observed after the treatment phase sustained across the follow up period of 3 months as well. To substantiate the effectiveness of the prescribed Ayurvedic treatment protocol in decelerating the osteoarthritis onset in a traumatic knee injury requires long term followups. Yet we have documented some positive leads from this report wherein Ayurvedic treatments may be adopted for effective and non-invasive rehabilitation of knee ligament injuries ranging from partial to complex origin and also in decelerating the risk of developing early osteoarthritis.

\section{KEY WORDS}

Ayurvedic management; knee ligament injury; rehabilitation. 


\section{BACKGROUND}

The knee, a compound synovial joint is the largest weight bearing joint which plays a significant role while adopting major routine postures and activities as a part of daily living such as sitting, walking and running. Thus, an injury to the knee adversely affects the quality of life of an individual irrespective of his/her age, gender and occupation. The function and stability of the knee in fact depends on specific muscles, ligaments, cartilage, synovial and other connective tissues (1). The most common knee injury observed in clinical practice is Anterior Cruciate Ligament (ACL) tear which is about $86.5 \%$, followed by Lateral \& Medial meniscal injuries which are around $78.24 \%$ (2). At times multi ligamentous knee injuries comprising of a wide range of ligaments and intra articular injury patterns are also reported in orthopedic clinics. There are operative methods aiming at anatomical reconstruction and non-operative treatment strategies for rehabilitation and recovery to the pre-injury status and at delaying the post traumatic osteoarthritis onset (3).

A manuscript on multi ligamentous knee injuries, concluded that, the effectiveness of treatments adopted in knee injuries remained controversial due to lack of prospective comparative clinical outcome studies and patient reported outcome. It also suggested the need of individualized rehabilitation protocols towards expected outcomes (4). A literature review on conservative or surgical treatments in anterior cruciate ligament tears observed that, the concept of reduced chances of further meniscal lesions in a surgically reconstructed ACL may not be just because of the intervention but may also result from a decrease in strenuous activities post-surgery (5). It is estimated that $60.2 \%$ of sport person does not return to strenuous activities after an anatomical reconstruction of their injured knee (2). The aforementioned literature review concluded that there was not enough evidence to recommend a reconstruction surgery more than a systematic neuromuscular rehabilitation in ligament injuries of knee. Also, whatever be the treatment modality the chances of post traumatic osteoarthritis could also not be denied. Quadriceps weakness, flexion contractures and patella femoral pain etc. post a knee injury hamper the activities of daily living to a significant extent even after adopting surgical correction or neuromuscular rehabilitation (5).

Susruta Samhita, an Ayurvedic treatise details various surgical, parasurgical and other manipulative techniques intended to restore and rehabilitate injured joints and other connective tissues (6). An overview of various forms of bandages and immobilizing techniques is found in this textbook. Current Ayurvedic clinical practices in such joint pathologies has evolved from these conventional methods and have been upgraded to patient centered quality care intending restoration to the activities of daily living.

We report an Inpatient level observation of 20 patients admitted at National Ayurveda Research Institute for Panchakarma, Cheruthuruthy, Kerala; diagnosed with injuries to the ligaments of knee following which who underwent Ayurvedic treatment protocol. In concerned patients with Ayurvedic treatments that comprised of internal administration of specific medicaments and external therapies we noted significant improvement in the parameters of pain, swelling and functional disability of the knee joint. Patients were able to return to activities of daily living with improved joint stability. This suggests the applicability of Ayurvedic healthcare approaches in joint injuries of sports or non-sports origin. Although Ayurvedic physicians exhibit clinical expertise in rehabilitating acute or subacute traumatic joint disorders, neuromuscular and connective tissue pathologies; minimal effectiveness studies are published in this arena. Ayurvedic therapies also hold substantial scope in the field of Sports Medicine. This observation intends to report the effectiveness of Ayurvedic treatment strategies in ligament injuries of knee.

\section{METHODS}

This is an observational report of 20 cases admitted in NARIP, Cheruthuruthy between the time period May to September 2019 diagnosed with knee ligament injuries ranging from partial to complex ones and who underwent Ayurvedic treatment protocol. Information on the knee injury was recorded based on the patient history and supportive radiological report. Personal information such as age, weight, height, and occupation were recorded. Knee Outcome Survey (KOOS) (7) and International Knee Documentation Committee (IKDC)- subjective evaluation score 8 were used to determine the extent of insult with regards to activities of daily living and involvement in sports and recreational activities. Person centered stage wise administration of Ayurvedic medicaments and external therapies were carried out for the concerned patients (table I).

The outcome measures of change in the KOOS and IKDC scores were analyzed pre-treatment [a1], post-treatment [a2] and after a follow-up [a3] of 3 months. Data analysis was carried out using Statistical Package for Social Sciences (SPSS). The ordinal data was subjected to Friedman's test. Post Hoc comparisons were carried out using Wilcoxon test (with Bonferroni correction). Results with p-value $<0.01$ were considered significant. 
Table I. Person centered stage wise management of the symptoms in knee ligament injury.

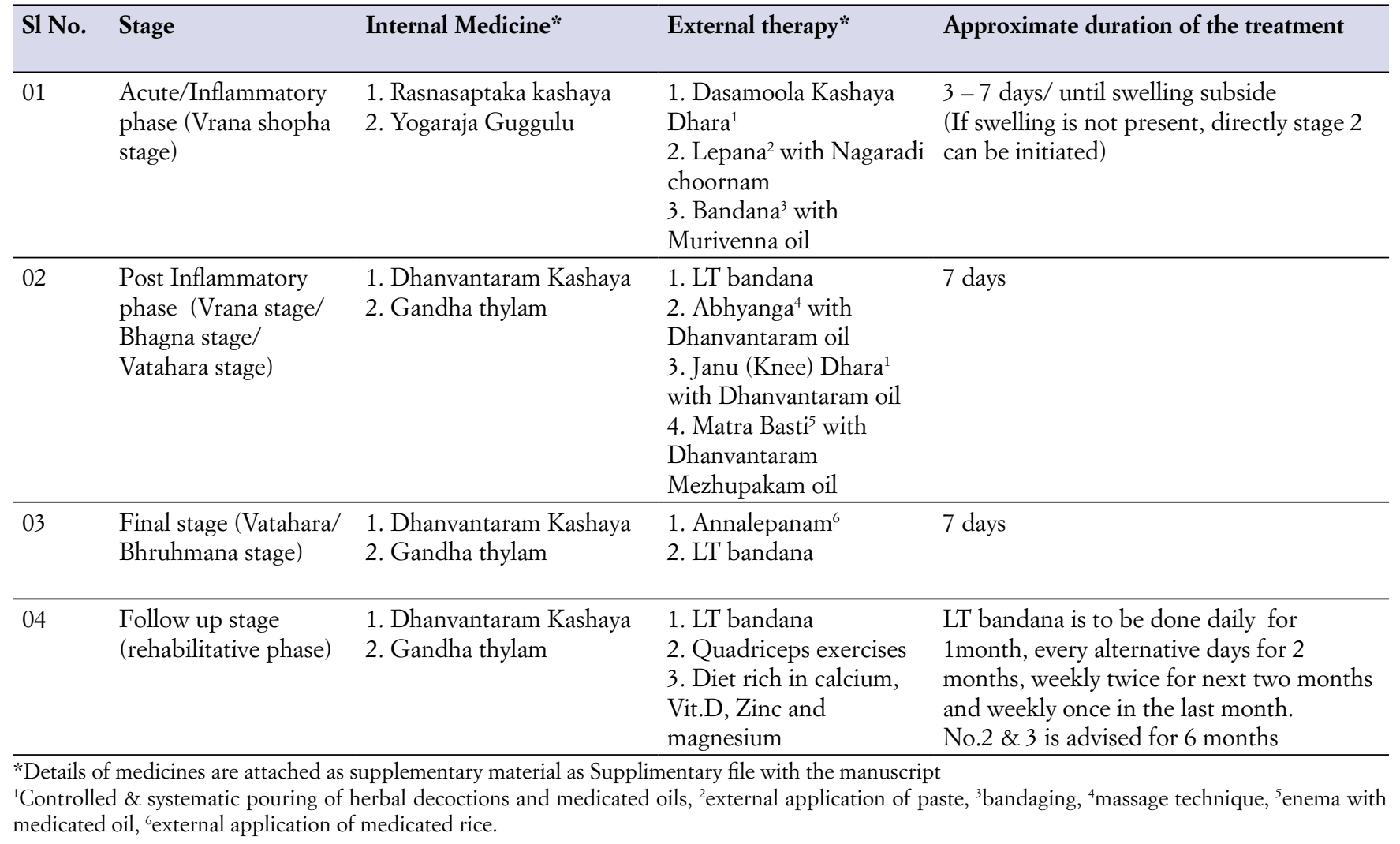

Selected internal medicines (table I) and medicines for external therapies were procured from a GMP certified company.

The external therapies namely Abhyanga (massage technique), Lepana-Annalepana (external applications, figures 11, 12,13\&... \.. $\backslash$ Photos \& Videos $\backslash$ Video Rec.2 (Annalepanam).mp4), Kashaya dhara -Taila dhara (controlled \& systematic pouring of herbal decoctions and medicated oils figures 8, 9 \&... \.. \Photos \& Videos $\backslash$ Video Rec.1 (Janu dhara).mp4), Matra Basti (enema with medicated oils) and Bandhana (bandaging techniques, figure 10) were administered in the Panchakarma theatres of the Institute.

\section{OBSERVATIONS}

\section{Demography}

Out of 20 patients observed, females and males represented about $45 \%$ and $55 \%$ respectively of the total sample. While considering the nature of work that the concerned patients adopted as a part of daily living; $20 \%$ of the patients were indulged in heavy labour (building workers and the like), $55 \%$ of the patients executed moderate labour (such as a home maker) and the remaining 25\% had sedentary lifestyles (indulging in long hours of desk work).

Other characteristics considered were variables such as age, height, weight and body mass index (BMI) for which the mean, standard deviation, range and Confidence intervals were analyzed (table II).

\section{Type and extent of knee ligament insult}

Based on type of ligaments injured; 14 patients were recorded with meniscal tear and the remaining 06 patients presented with cruciate ligament injury (table III).

\section{Effectiveness of the Ayurvedic treatment protocol - KOOS and IKDC scores}

The effectiveness of the Ayurvedic treatment protocol were assessed in terms of percentage increase in KOOS and IKDC scores recorded post treatment (after treatment and after the follow up period of 3 months, table IV) 


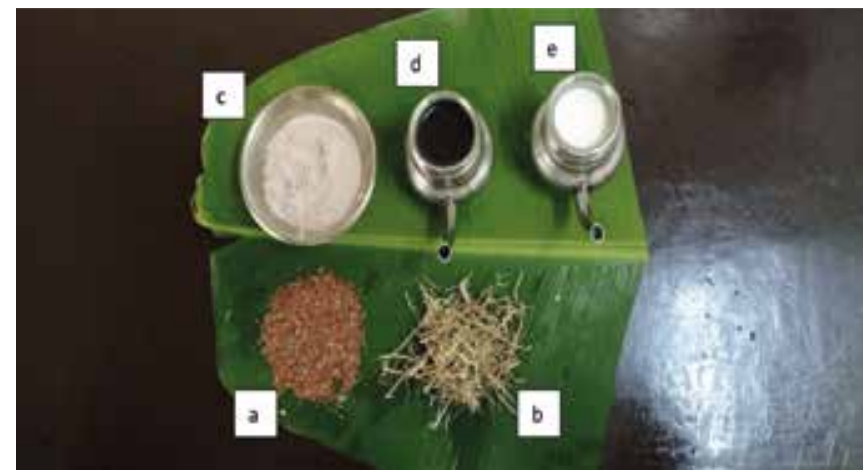

Figure 11. Method of preparation of Medicated njavara rice paste:

'Njavara or shashtika-sali' (Oryza Sativa L.) is a traditional medicinal rice grown in Southern part of India which is extensively used in Ayurvedic treatments. The rice is cooked in a decoction prepared with milk and a herb namely bala (SidaretusaLinn) and applied over the affected area.

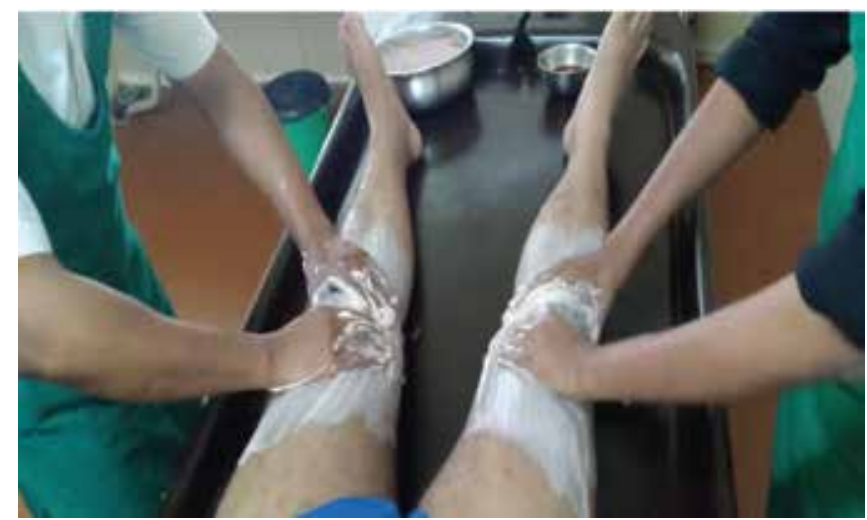

Figure 13. Massaging both the knee joints with medicated njavara rice paste. Refer to video recording no.2.

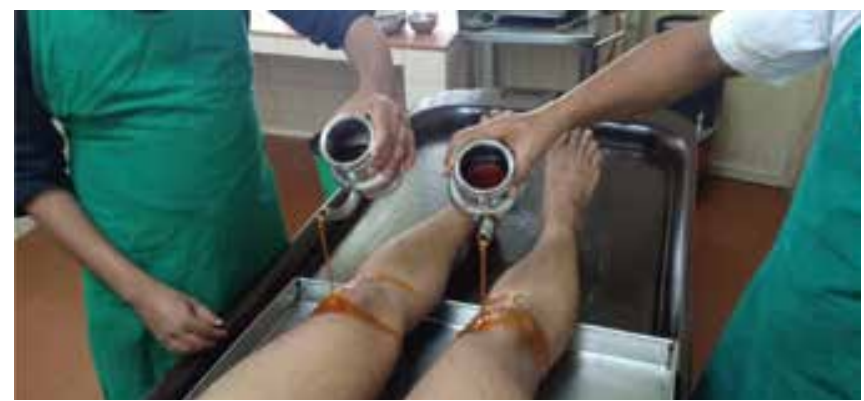

Figure 9. Procedure of Janudhara - with medicated oils, Refer to video recording no.1.

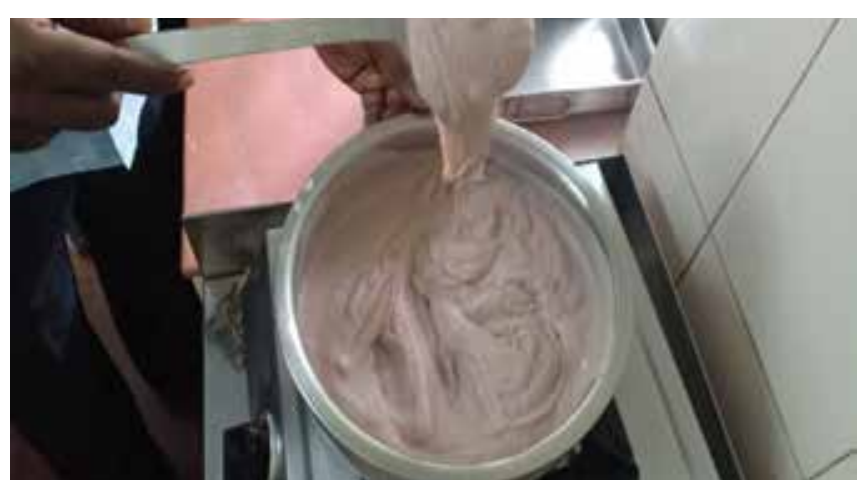

Figure 12. Medicated Njavara rice paste.

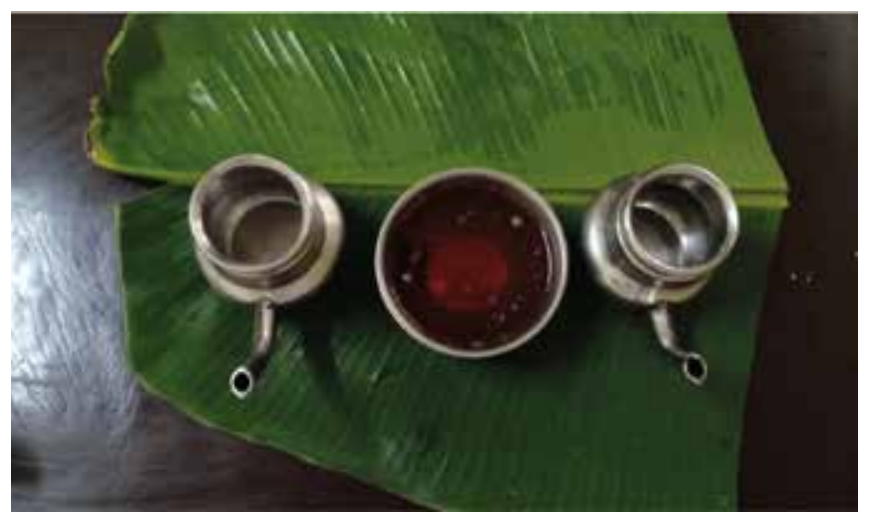

Figure 8. Materials required for Janudhara with medicated oil.

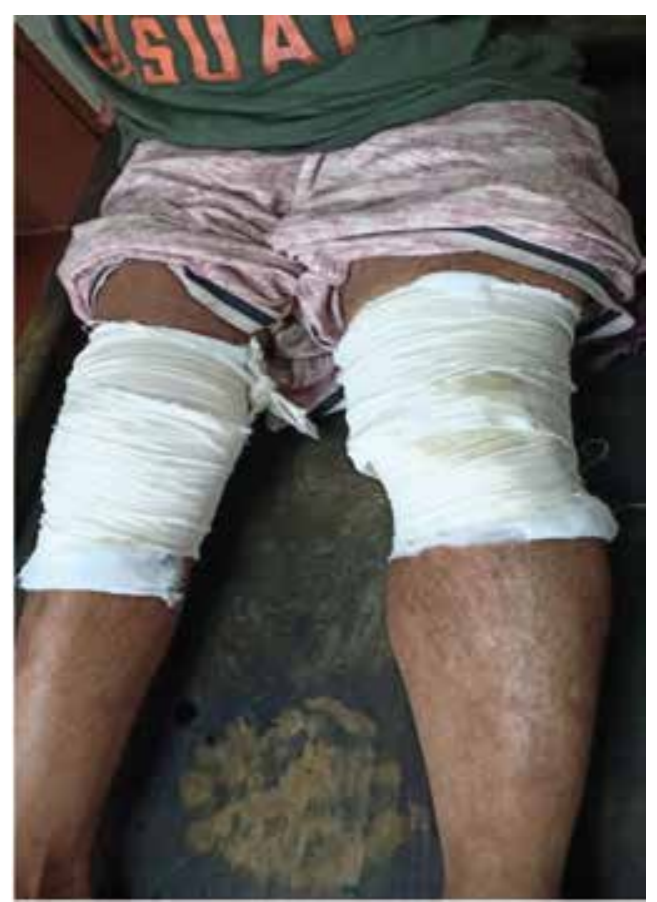

Figure 10. Bandaging technique.

Muscles, Ligaments and Tendons Journal 2020;10 (3) 
Table II. General Characteristics of the sample.

\begin{tabular}{cccc}
\hline Sample variables & MeanSD & Range & 95\% CI \\
\hline Age & 38.6512 .96 & 52 & $(32.97,44.33)$ \\
\hline Height & 152.26 .89 & 25 & $(149.18,155.22)$ \\
\hline Weight & 63.659 .09 & 35 & $(59.67,67.63)$ \\
\hline BMI & 27.574 .16 & 18.6 & $(25.75,29.39)$ \\
\hline
\end{tabular}

Table III. Extent of knee ligament insult.

\begin{tabular}{|c|c|c|c|c|c|}
\hline Type of injury & Complete & Percentage & Partial & Percentage & Total \\
\hline $\begin{array}{l}\text { Medial menisceal / Lateral } \\
\text { menisceal tear }\end{array}$ & 03 & 23 & 10 & 77 & 13 \\
\hline
\end{tabular}

Table IV. Summary of Scores.

\begin{tabular}{llll}
\hline Score & $\begin{array}{l}\text { Pre-treatment } \\
\text { Median Score (IQR) }\end{array}$ & $\begin{array}{l}\text { Post-treatment } \\
\text { Median Score (IQR) }\end{array}$ & $\begin{array}{l}\text { Follow-Up } \\
\text { Median Score (IQR) }\end{array}$ \\
\hline KOOS-Pain & $49.50(42.00-68.00)$ & $81.00(71.40-91.25)$ & $80.00(76.25-91.25)$ \\
\hline KOOS-Symptom & $55.50(46.00-69.25)$ & $91.00(71.00-96.00)$ & $93.00(79.00-99.00)$ \\
\hline KOOS-ADL & $57.50(44.50-96.25)$ & $87.50(69.75-96.25)$ & $86.50(81.25-96.00)$ \\
\hline KOOS Sport/ Rec & $32.50(11.25-48.75)$ & $72.50(51.25-78.75)$ & $72.50(51.25-85.00)$ \\
\hline KOOS-QOL & $31.00(19.00-44.00)$ & $63.00(40.25-78.00)$ & $59.50(44.00-83.25)$ \\
\hline Overall KOOS Score & $49.50(42.00-68.00)$ & $81.00(71.50-91.25)$ & $80.00(76.25-91.25)$ \\
\hline IKDC Score & $34.45(26.13-42.80)$ & $70.70(53.73-77.00)$ & $75.85(62.63-88.80)$ \\
\hline
\end{tabular}

\section{KOOS score}

The outcome measures of change in KOOS Score were analyzed using the prescribed sub parameters namely pain, other symptoms, ADL, sport/rec, quality of life and overall KOOS Score. The scores were measured pre-treatment (a1), post-treatment (a2) and after a follow-up of 3 months (a) - (figures $1,2,3,4,5,6)$. For each of the study variable, it was observed that the KOOS score differed significantly with respect to pre and post treatment phases, whereas no significant change was observed between the post-treatment and follow-up scores. These results suggested that the scores improved significantly after the treatment phase and the improved scores were maintained at follow-up period of three months.

Friedman's test was conducted on a sample of size $n=20$ for each of the study variables (table V). There was a statistically significant difference in scores measured during the three periods for pain, symptoms, ADL, sports/rec, QoL and overall score.
Further, results of the Post hoc analysis using Wilcoxon signed-rank tests at Bonferroni-adjusted significance level $(\mathrm{p}<0.017)$ for the sub parameters between a1 \& a2 phase assessments and a1 \& a3 showed significant difference at $1 \%$ level. However no significant difference was observed in the scores measured during phase a2 \& a3 (table VI).

These results showed that the scores improved significantly after the treatment phase and were consistent even after a follow-up period of three months. The effect sizes for each of these variables suggested a moderate to high clinical significance.

\section{IKDC scores}

As for KOOS, a Friedman's test was conducted to compare the IKDC scores measured at a1 phase, a2 \& at a3 (tables $\mathrm{V}$, figure 7). There was a statistically significant difference in scores measured during the three periods with $\chi 2(2)=$ $32.430, \mathrm{p}=0.000<0.01$. Post hoc analysis with Wilcoxon 


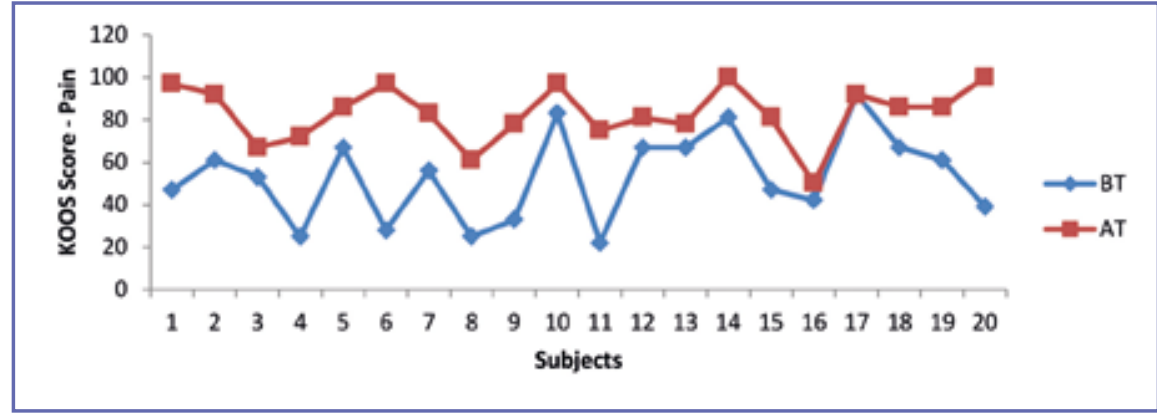

Figure 1. KOOS pre-treatment and post-treatment scores for pain.

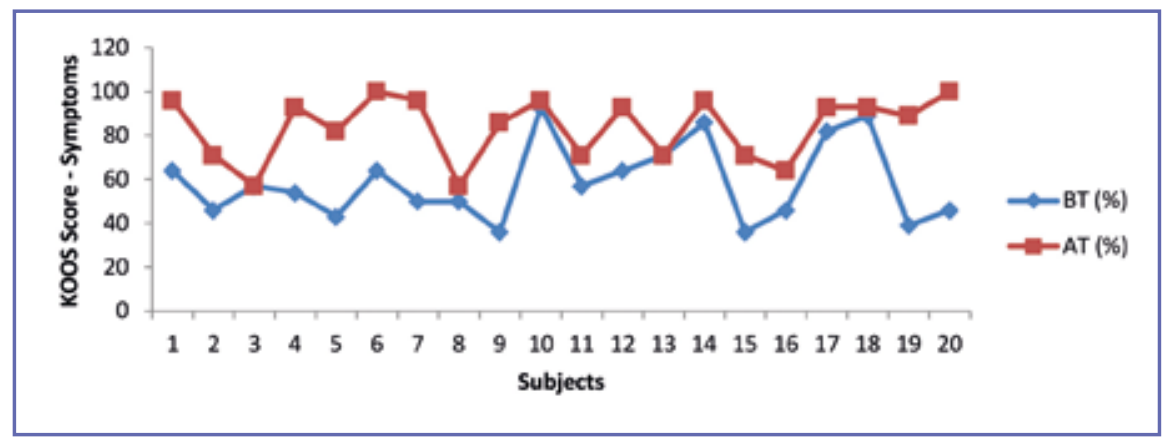

Figure 2. KOOS pre-treatment and post-treatment scores for other symptoms.

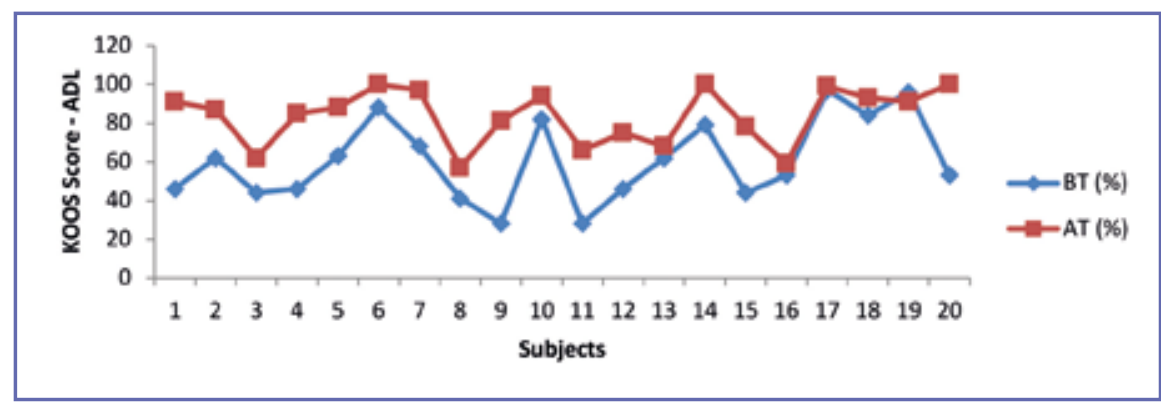

Figure 3. KOOS pre-treatment and post-treatment scores for ADL.

Table V. Friedman's test results on KOOS parameters and IKDC scores after treatment $(n=20)$.

\begin{tabular}{lll}
\hline Score & Chi square Value & P-value \\
\hline KOOS-Pain & 26.083 & $<0.01^{*}$ \\
\hline KOOS-Symptom & 27.634 & $<0.01^{*}$ \\
\hline KOOS-ADL & 17.636 & $<0.01^{*}$ \\
\hline KOOS Sport/ Rec & 26.587 & $<0.01^{*}$ \\
\hline KOOS-QOL & 19.541 & $<0.01^{*}$ \\
\hline Overall KOOS Score & 28.737 & $<0.01^{*}$ \\
\hline IKDC Score & 32.430 & $<0.01^{*}$
\end{tabular}

*Results significant at $1 \%$ level signed-rank tests at Bonferroni-adjusted significance level (0.017) revealed that IKDC scores for symptoms that measured changes between a1 \& a2 scores showed significant results with $\mathrm{Z}=-3.920, \mathrm{p}=0.000<0.017$, with effect size $r=-0.619$ and between a1 \& a3 with $\mathrm{Z}=-3.922, \mathrm{p}=0.000<0.017$; with effect size $r=-0.620$. As in KOOS the effect sizes, for each variable suggested a moderate to high clinical significance. No significant difference was observed in the scores measured a2 \& a3 with $\mathrm{Z}=-2.234, \mathrm{p}=0.025>$ 0.017. Like KOOS observations, these results too suggested that the scores improved significantly after the treatment and the improved scores were consistent after a follow-up period of three months (table VI).

Some patients reported at the OPD after a period of 6 months $(8 / 20)$ to 1 year $(9 / 20)$. In those selected patients, Wilcoxon test was conducted to determine whether there was a significant difference in the KOOS-IKDC scores observed after such long-term followups (tables 11, 12). The results indicated that scores recorded after treatment showed no significant difference even after a follow- up period of 6 months to 1 year.

\section{Effectiveness of the treatment protocol with respect to sample variables}

Age, gender, nature of work and BMI were assessed with respect to KOOS and IKDC scores (tables VII,VIII,IX). Here, the percentage increase in IKDC and KOOS score after the treatment were more evident in elderly people than others. But, as the number of elderly patients was less $(05 \%)$ compared to the other age groups, this may not be generalized. While considering the gender wise distribution and the effectiveness of the treatment, percentage increase in mean KOOS and IKDC scores were more evident in females. 


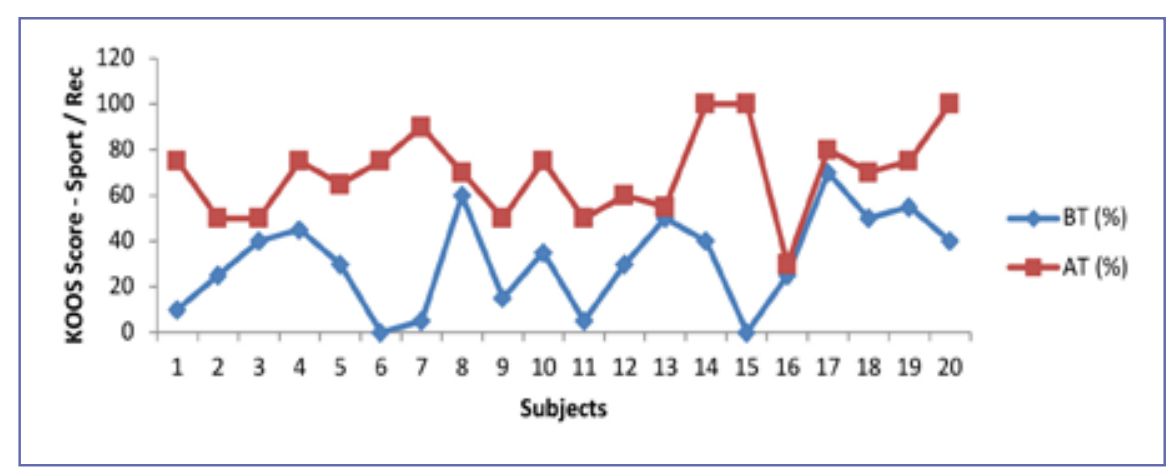

Figure 4. KOOS pre-treatment and post treatment scores for sports/rec.

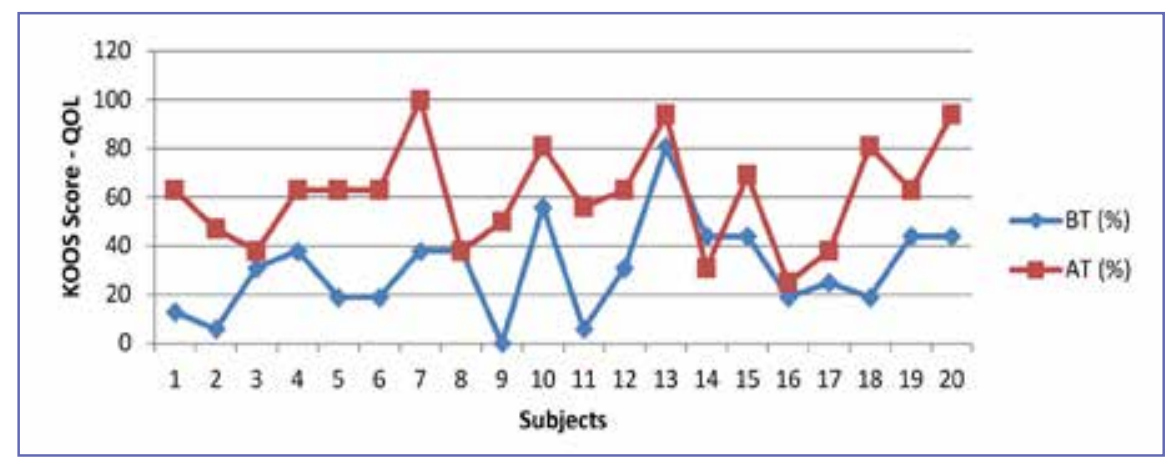

Figure 5. KOOS pre-treatment and post treatment scores for QoL.

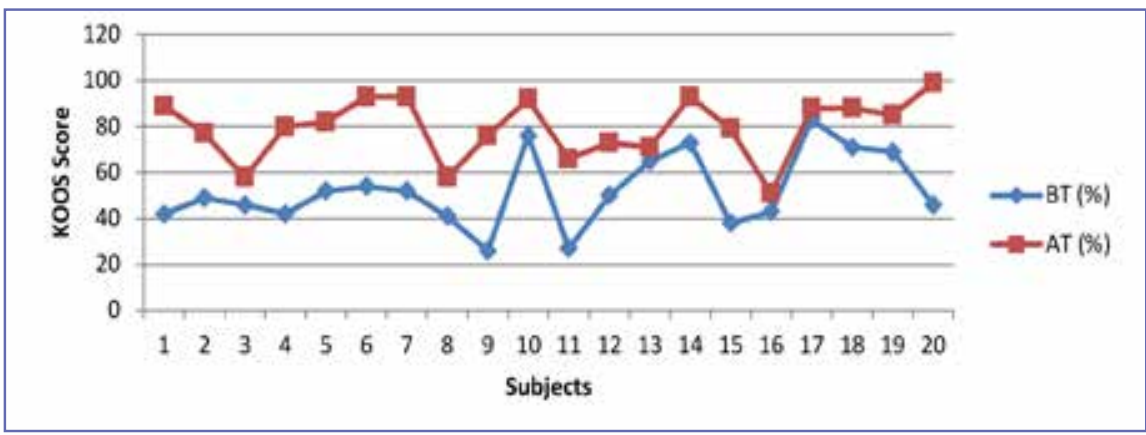

Figure 6. KOOS pre-treatment and post-treatment over all scores.

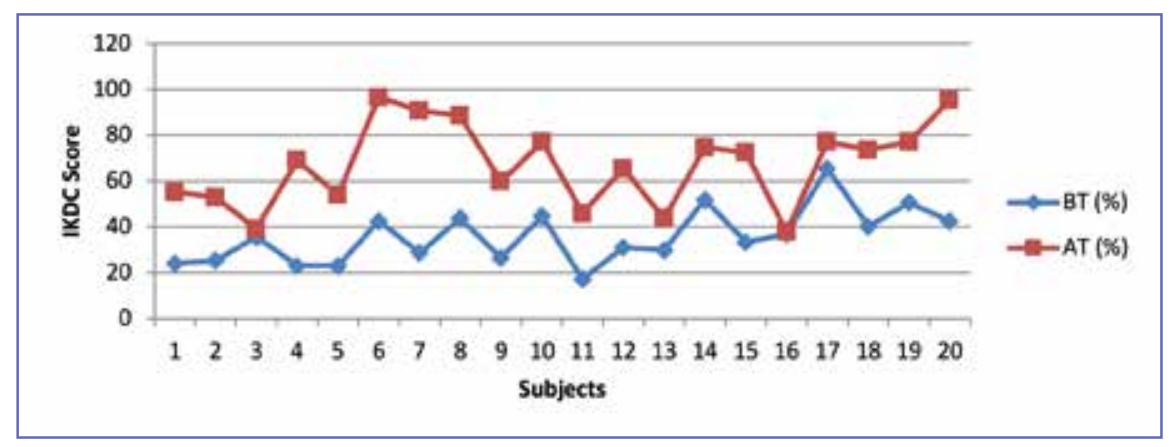

Figure 7. IKDC pre-treatment and post treatment scores.
Further, patients who indulged in moderate labour showed a better response to the treatment protocol in terms of improvement scores on an average, with respect to IKDC, whereas those who lead sedentary lifestyles responded more as far as KOOS scores were considered

While considering the type of ligament injury and the effectiveness of the treatment adopted, it was found that in patients with complete meniscal tear, there was a significant increase in KOOS scores after adopting the treatment protocol. In case of IKDC score, significant improvement in mean percentage score was evident in patients with partial meniscal tear (table X)

Considering the variable body mass index (BMI) and effectiveness of the treatment adopted, measured using KOOS and IKDC scores, there was no significant correlation (Spearman's correlation co-efficient (KOOS)rho $=0.036, \mathrm{p}$ value $=0.880>0.01$ and (IKDC) rho $=-0.032, \mathrm{p}$ value $=0.894>0.01$ ) between BMI and the improvement in scores.

\section{DISCUSSION}

\section{Janu sandhi marma (the knee joint)}

Ayurveda is an established complimentary healthcare service that originated in India. Because of its person centered diagnostic methods and personalized treatment modalities, it is gaining global attention from various health related communities. WHO is significantly contributing towards upgrading the traditional practices in Ayurvedic Sciences to Evidence Based Medicine considering the increase in demand of Ayurvedic herbals among the global patient community (9). Susruta Samhita is an ancient textbook that was written as early as about 1000 BC, most of which was dedi- 
Table VI. Post hoc analysis using Wilcoxon signed-rank tests at Bonferroni-adjusted significance level $(p<0.017)$ for the KOOS sub parameters and IKDC scores.

\begin{tabular}{|c|c|c|c|c|c|c|}
\hline \multirow[t]{2}{*}{ Score } & \multicolumn{2}{|c|}{ Phase $a 1-a 2$} & \multicolumn{2}{|c|}{ Phase a1 - a3 } & \multicolumn{2}{|c|}{ Phase a2 - a3 } \\
\hline & Z Value & $\begin{array}{c}\text { P-value \& Effect } \\
\text { size }\end{array}$ & Z Value & $\begin{array}{l}\text { P-value \& } \\
\text { Effect size }\end{array}$ & Z Value & P-value \\
\hline KOOS-Pain & -3.826 & $\begin{array}{l}<0.01^{*} \\
-0.605\end{array}$ & -3.463 & $\begin{array}{l}<0.01^{*} \\
-0.548\end{array}$ & -1.197 & $>0.01$ \\
\hline KOOS-Symptom & -3.724 & $\begin{array}{l}<0.01 \\
-0.588 \\
\end{array}$ & -3.812 & $\begin{array}{l}<0.01 * \\
-0.603\end{array}$ & -0.385 & $>0.01$ \\
\hline KOOS-ADL & -3.847 & $\begin{array}{l}<0.01 * \\
-0.608\end{array}$ & -3.398 & $\begin{array}{l}<0.01 * \\
-0.537\end{array}$ & -0.071 & $>0.01$ \\
\hline KOOS Sport/ Rec & -3.923 & $\begin{array}{l}<0.01 * \\
-0.620\end{array}$ & -3.717 & $\begin{array}{l}<0.01^{*} \\
-0.587\end{array}$ & -0.057 & $>0.01$ \\
\hline KOOS-QOL & -3.699 & $\begin{array}{l}<0.01 * \\
-0.585\end{array}$ & -3.219 & $\begin{array}{l}<0.01^{*} \\
-0.509\end{array}$ & -0.341 & $>0.01$ \\
\hline Overall KOOS Score & -3.921 & $\begin{array}{l}<0.01 * ; \\
-0.619\end{array}$ & -3.771 & $\begin{array}{l}<0.01 * \\
-0.596\end{array}$ & 0.00 & $>0.01$ \\
\hline IKDC Score & -3.920 & $\begin{array}{l}<0.01 * ; \\
-0.619\end{array}$ & -3.922 & $\begin{array}{l}<0.01^{*} \\
-0.620\end{array}$ & -2.234 & $>0.01$ \\
\hline
\end{tabular}

*Results significant at $1 \%$ level

Table VII. Age wise distribution and percentage changes in IKDC and KOOS scores.

\begin{tabular}{llll}
\hline Age group & $\begin{array}{l}\text { Frequency } \\
\text { (in \%) }\end{array}$ & \multicolumn{2}{c}{ \% Increase in Score } \\
\cline { 3 - 4 } & IKDC & KOOS \\
\hline Young & 20 & 26.5 & 33.93 \\
\hline Adults & 75 & 26.8 & 29.91 \\
\hline Elderly & 5 & 38 & 46 \\
\hline
\end{tabular}

Table IX. Amount of labour/strenuous activities and percentage changes in IKDC and KOOS scores.

\begin{tabular}{llll}
\hline $\begin{array}{l}\text { Amount } \\
\text { of labour/ } \\
\text { strenous } \\
\text { activities }\end{array}$ & $\begin{array}{l}\text { Frequency (in } \\
\%)\end{array}$ & $\begin{array}{l}\% \text { increase in } \\
\text { IKDC Score }\end{array}$ & $\begin{array}{l}\% \text { increase } \\
\text { in KOOS } \\
\text { score }\end{array}$ \\
\hline $\begin{array}{l}\text { Heavy } \\
\text { Labour }\end{array}$ & 20 & 19 & 29.33 \\
\hline $\begin{array}{l}\text { Moderate } \\
\text { Labour }\end{array}$ & 55 & 32.45 & 31.9 \\
\hline $\begin{array}{l}\text { Sedentary / } \\
\text { Desk Job }\end{array}$ & 25 & 23.4 & 35.88 \\
\hline
\end{tabular}

cated to surgical and parasurgical manipulations. Kshara sutra (medicated seton), kshara karma (caustic alkali), agni karma (cautery), rakta moksha (blood-letting), plastic reconstruction of facial characters with special mention to
Table VIII. Gender wise distribution and percentage changes in IKDC and KOOS scores.

\begin{tabular}{lllc}
\hline Gender & \multicolumn{3}{c}{ \% Increase in Score } \\
\cline { 2 - 4 } & $\begin{array}{l}\text { Frequency } \\
\text { (in \%) }\end{array}$ & IKDC & KOOS \\
\hline Female & 45 & 35.22 & 35.53 \\
\hline Male & 55 & 20.81 & 28.23 \\
\hline
\end{tabular}

Table X. Mean percentage score improvement and extent of knee ligament insult.

\begin{tabular}{lllll}
\hline $\begin{array}{l}\text { Mean } \\
\text { percentage } \\
\text { score } \\
\text { improvement }\end{array}$ & MM / LM Tear & ACL tear & \\
\cline { 2 - 5 } & Complete & Partial & Complete & Partial \\
\hline KOOS & 38.67 & 28 & 22.33 & 17.25 \\
\hline IKDC & 32.60 & 34.73 & 24.93 & 26.47 \\
\hline
\end{tabular}

ear, nose and lip, manipulations in bhagna (fractures) and sandhimoksha (joint dislocations) such as aanchana (traction), peedana (compression), samkshepa (immobilization) and bandhana (bandaging) have been explained in this 
Table XI. Wilcoxon values -KOOS \& IKDC post-treatment and at follow-up of 6 month in selected patients.

\begin{tabular}{lll}
\hline Score & \multicolumn{2}{l}{$\begin{array}{l}\text { Comparison of scores measured After } \\
\text { treatment and at Follow-up }\end{array}$} \\
\hline Z Value & P-value \\
\hline KOOS-Pain & -2.038 & $0.042>0.01$ \\
\hline KOOS-Symptom & -0.524 & $0.600>0.01$ \\
\hline KOOS-ADL & -1.193 & $0.233>0.01$ \\
\hline KOOS Sport/ Rec & -1.355 & $0.176>0.01$ \\
\hline Overall KOOS Score & -1.183 & $0.726>0.01$ \\
\hline IKDC Score & -1.684 & $0.237>0.01$ \\
\hline
\end{tabular}

textbook. Different types of surgical instruments, suturing materials, usage of twine for ligature, different types of bandaging techniques, dressing materials, splints for fractured bones too are mentioned. Bandaging techniques were specific to the severity of the condition, seasonal variations and the anatomical sites (10) (Sootrasthana 16/ 86-89).

Marmas (vital points) were considered as the conjuncture site of multiple anatomical structures as asthi (bone), sandhi (joints), peshi (muscles) sira (blood vessels) and snayu (ligaments, tendons or anatomical suture lines). There are five different types of marmas of which one is sandhi marma (Joints) (10) (Sharirasthana 6/369-370).

Janu sandhi or the knee joint is considered as a sandhi marma, which when traumatized (janumarma abhighata) results in khanjatva (disability/ weakness) (10) (Sharirasthana 6/372-373). Based on the prognosis of the knee insult, the knee is considered as a vaikalyakara marma. Vaikalyakara marmas are those vital points in the human body which when traumatized results in permanent disability. The specialty of vaikalyakara marma such as the knee joint is that a timely and an appropriate intervention from a good physician shall restore the activities of the tissue afflicted at this site (10) (Sharirasthana 6/370).

\section{Expected effectiveness of procedures}

The treatment procedure of "dhara" represents the rhythmic and systematic pouring of medicaments over specific body parts or the entire body surface for a stipulated time. In case of knee ligament injuries, two specific dhara procedures are adopted; the kashaya dhara (pouring of herbal decoctions) and the taila dhara (pouring of medicated oils (figures 8, 9). Kashaya dhara is selected in an inflammatory phase and taila dhara is appropriate where inflam-
Table XII. Wilcoxon values - KOOS and IKDC posttreatment and at follow-up of 1year in selected patients.

\begin{tabular}{lll}
\hline Score & \multicolumn{2}{l}{$\begin{array}{l}\text { Comparison of scores measured } \\
\text { After treatment and at Follow-up } \\
-1 \text { year }\end{array}$} \\
\hline & Z Value & P-value \\
\hline KOOS-Pain & -0.105 & $0.917>0.01$ \\
\hline KOOS-Symptom & -0.845 & $0.398>0.01$ \\
\hline KOOS-ADL & -0.593 & $0.553>0.01$ \\
\hline KOOS Sport/ Rec & -1.119 & $0.263>0.01$ \\
\hline KOOS-QOL & -1.183 & $0.237>0.01$ \\
\hline Overall KOOS Score & 0.508 & $0.611>0.01$ \\
\hline IKDC Score & -1.125 & $0.260>0.01$ \\
\hline
\end{tabular}

matory signs are minimal, i.e., in a degenerative phase. The medicines selected for herbal decoction in Kashaya dhara is Dasamoola (roots of ten different herbs). Dasamoolakashaya is effective in reducing swelling and other signs of inflammation (11) (Guduchyadivarga, 49). An animal study conducted by Parekar et al has proven the analgesic and anti-inflammatory potential of Dasamoola (12). Taila dhara is done with Dhanvantaram oil which is specifically indicated in traumatic injuries is expected to strengthen the musculoskeletal framework (13) (Sharirasthana, 2/47-52).

"Lepana" refers to local application of medicated pastes. Application of paste or the lepa is the first and foremost treatment for inflammation (10) (Sutrasthana, 18/3). Nagaradi choornam (the herbal combination of powdered drugs) along with tamarind leaf juice was used here as lepa. The ingredients in Nagaradi choorna (Suppl. file) possess anti-inflammatory and analgesic properties14 (ChurnaKalpana). After mixing the medicated powder with the prescribed leaf juice, the mixture is heated and when warm, is applied over the afflicted joint. Tamarind juice possesses anti-inflammatory, analgesic and antinociceptive effects (15) and thus is expected to enhance the therapeutic effects of the herbal drugs.

"Abhyanga" refers to specific massaging techniques with medicated oils. After the acute/inflammatory phase, abhyanga is specifically indicated in fractures and other joint pathologies (16) (Sutrasthana, 3/54-55). Here, abhyanga was done with Dhanwantaram oil (18) (Suppl. file).

Matra-basti is the trans-rectal administration of medicaments especially medicated oils, in predetermined doses. It is expected to reduce the symptoms of pain and stiffness and it also strengthens musculoskeletal systems. Dhanwantaram Mezhukupaka (Mezhukupaka is a special preparation with medicated oils exclusively prepared for transrectal administartion) was selected here for the matra basti procedure. 
Bandhana referes to unique bandaging techniques that immobilizes the joint and thereby promotes the healing process (10) (Sootrasthana 16-17). Susrutha Samhita has given prime importance to the bandaging techniques in the treatment of injuries. He has given detailed description of various types of bandage materials and fourteen types of bandaging techniques (10) (Sutrasthana, 18/86-89). Here in the management of ligament injuries, bandaging was done initially i.e., in the inflammatory phase with Murivenna oil (Suppl. file). Murivenna is medicated oil which is used for healing contusions, wounds and fractures. The medicines used in the preparation of Murivenna possess anti-inflammatory properties (17).

In the post inflammatory phase, bandaging was done with specific herbal combination named as LT bandhana (figure 10); (suppl. file). LT bandhana possess anti-inflammatory, analgesic, antioxidant, tissue regeneration and joint strengthening properties $(14,18,19)$. Cocunut meat scrap and egg white used in this bandage is rich in protein, trace minerals $(\mathrm{Mg}, \mathrm{Zn})$ and vitamins which help in wound healing, tissue building, collagen formation, reduction of inflammation and strengthen the bone, muscles and tendons (20, 21). On bandaging the joint with medicines mixed with egg white and coconut meat scrap, in addition to immobilizing the joint; enough nutrition is also being supplied transdermally which may accelerate the tissue regeneration and strengthen ligaments, muscles, tendons and thereby it improves the joint stability.

Annalepa refers to application of a paste prepared out of cooked 'njavara' a medicinal rice variety, over specific body parts. This is a method administered to nourish the joint, enhance joint stability and delay the onset of post traumatic osteoarthritis (figures 11,12,13).

The medicinal properties of njavara may be attributed to its anti-oxidant22and ant-i inflammatory activities23. High thyamine and $\mathrm{Ph}, \mathrm{K}, \mathrm{Na}, \mathrm{Ca}, \mathrm{Mg}$ contents in the njavara rice indicates the reason why it is found clinically effective in degenerative joint pathologies, muscular atrophies and neuritis.

\section{Ayurvedic intervention and observed results in knee ligament injuries}

Ayurvedic interventions show clinically significant improvements in traumatic/degenerative joint pathologies with special mention in delaying osteoarthritis onset. The approach is usually patient centered with individualized treatment guidelines and medicaments. This observatory report is a primary analysis based on patient reported outcomes after Ayurvedic treatments in knee ligament injuries.

Do Kyung Kim (24) discussed regarding the compromised extensor muscle strength and reduced improvement in females compared to males after reconstruction surgery, making them difficult to rehabilitate (24). But in this report, after the treatment phase and while the follow up period, improved knee indices in form of improved KOOS and IKDC scores were found in female patients compared to male counterparts. This is a positive lead.

While assessing the KOOS-IKDC scores, the treatment protocol gave statistically significant results after the treatment phase and the improved scores were consistent even after the follow up period. Clinically also the patients reported improved joint stability and reduction in symptoms such as pain, swelling and joint stiffness.

Ayurvedic treatment was more significant in improving KOOS and IKDC scores in meniscal injuries than cruciate ligament tears. Interestingly, in patients with partial meniscal injuries, changes in IKDC scores were more significant than KOOS scores. Conversely, in complete meniscal injuries changes in KOOS scores were rather more significant. Also, while considering the amount of labour that the patients engaged in as a part of daily living, those who indulged in moderate labour as homemakers got higher IKDC scores than KOOS scores after treatment. Conversely, those who led a sedentary lifestyle responded to the treatment with improved KOOS scores than IKDC scores. A probable reason for these observations may be the fact that KOOS scores are more concerned with scoring the total disability index with respect to symptoms of meniscal and ligament injuries like pain, swelling and stiffness than functional and stability status. IKDC subjective evaluation score emphasizes functional status with respect to activities of daily living/ indulge in strenuous activities. As patients with meniscal injuries responded more when compared to patients with cruciate ligament tears, it is inferred than Ayurvedic treatments improves the functional status of the joint by reducing the symptoms rather than imparting the functional stability.

Richard F Loesser (25) stated that elderly population were more vulnerable to traumatic knee injuries and if manifested were difficult to rehabilitate due to co morbidities such as sarcopenia and osteopenia25. But in this study, elderly participants reported significant relief in symptoms with improved joint stability after the treatment protocol. The statistical significance reported in this sample is not generalizable as the number of elderly patients was less compared to the other age groups, yet this seems a positive lead in rehabilitating knee injuries with Ayurvedic interventions in elderly.

While considering a significant variable namely the BMI which is related to rehabilitation of the knee injuries (26), knee being an important weight bearing joint; this report found no correlation between BMI of the patients and the 
extent of improvement in KOOS and IKDC scores. This is a crucial finding where the results were equally significant in all participants irrespective of their BMI.

\section{Limitations and recommendations}

This observatory report lacks radiological evidence after the treatment phase or follow up. A significant confounder namely, the nature of trauma (acute traumatic/ chronic degenerative) with respect to time of initiation of the treatment protocol in patients was not taken into account as these factors were not adequately represented in the sample. But out of curiosity a Mann Whitney $U$ test on improvement in KOOS and IKDC scores across the acute traumatic and chronic degenerative groups yielded insignificant results (KOOS- $U=34$, p-value $>0.01$; IKDC- $U=35.5$, p-value > 0.01 ) which meant the treatment was effective irrespective of the nature of trauma and time of initiation of treatment. But as afore mentioned, this cannot be generalized due to insufficient representation of this cofounder in the studied sample. Also, long term follow ups are very crucial in knee ligament injuries to collect data on incidence of osteoarthritis, indulgence in strenuous activities, functional indices with respect to activities of daily living etc. Some patients reported to the OPD as a part of long-term follow ups $(6$ months to 1 year), and the results indicated that the statistical significance noted after treatment sustained even after such longterm follow ups. This is a definite positive lead in knee rehabilitation. Yet it seems incorrect to generalize these finding as all patients did not turn up after such long-term follow ups. This study thus lacks such long term follow up data. Samples

\section{REFERENCES}

1. Gupton M, Terryberry RR. Anatomy, Bony Pelvis and Lower Limb, Knee. [Updated 2018 Dec 6]. In: StatPearls. Treasur Island (FL): StatPearls Publishing 2020 Jan.

2. John R, Dhillon MS, Syam K, Prabhakar S, Behera P, and H. Singh. Epidemiological profile of sports-related knee injuries in northern India: An observational study at a tertiary care centre. J Clin Orthop Trauma 2016 Jul-Sep; 7(3): 207-211.

3. Lynch AD, Chmielewski T, Bailey L, et al. Current Concepts and Controversies in Rehabilitation After Surgery for Multiple Ligament Knee Injury. Curr Rev Musculoskelet Med 2017 Sept; 10(3): 328-345

4. Cox CL, Spindler KP. Multiligamentous Knee Injuries - Surgical Treatment Algorithm. N Am J Sports Physs Ther 2008 Nov; 3(4):198-203.

5. Delince P, Ghafil D. Anterior cruciate ligament tears: conservative or surgical treatment? A critical review of the literature. Knee Surg Sports Traumatol Arthrosc 2012 Jan;20(1): 48-61.

6. Valiathan MS. The Legacy Of Susruta. Orient Longman $2007 ; 31$. with equal representation of all possible risk factors would help produce a stronger evidence for the findings.

There are effective Ayurvedic treatment strategies and rehabilitation techniques to treat acute, subacute and chronic knee ligament injuries which are of partial or complete origin. This observation gives a primary insight on specific non-invasive Ayurvedic treatments which are commonly practiced in knee ligament injuries that give promising results in knee joint rehabilitation by reducing symptoms of pain, swelling and stiffness and thereby restoration to the activities of daily living. Even such treatments may be adopted following a reconstruction surgery where knee joint stiffness and other symptoms prevail after surgery. Randomized clinical trials may be conducted to compare the efficacies of such person centered alternative medical approaches with standard treatments like reconstruction surgeries. Also, there is significant scope of integrative approaches in effective recovery where Ayurvedic treatment protocols may be added to standard reconstruction surgeries/ non-invasive rehabilitation techniques in injuries of sports or non-sports origin. Appropriate implementation, evaluation and interpretation of clinical findings are fundamental and crucial in case reporting (27). This report shall stand as a significant background to appropriately designed, implemented, evaluated and interpreted clinical trials of different traditional and alternative medical practices in musculo-skeletal disorders/ injuries of varied origin.

\section{CONFLICT OF INTERESTS}

The authors declare that they have no conflict of interests.

7. Roos EM, Lohmander LS. The Knee injury and Osteoarthritis Outcome Score (KOOS): from joint injury to osteoarthritis. Health Qual Life Outcomes 2003; 1:64.

8. Collins, Devyani Misra, Felson DT, Crossley KM, Roos EM. Measures of Knee Function. Arthritis Care Res (Hoboken) 2011 Nov; 63(011): S208-S228.

9. Anand Choudary and Neetu Singh. Contribution of world health organization in the global acceptance of Ayurveda). J.Ayurveda Integr Med 2011 Oct-Dec; 2(4): 179-186.

10. Yadavji TA, editor. Susrutha Samhita. Varanasi: Chaukamba Krishanadas Academy 2008.

11. Pandey GS, editor. Bhavaprakashanighantu. Varanasi: Chaukambha Bharati Academy 2004.

12. Parekar RR, Bolegave SS, Marathe PA, Rege NN. Experimental evaluation of analgesic, anti-inflammatory and anti-platelet potential of Dashamoola. J Ayurveda Integr Med 2015;6(1):1118.

13. Vaidya HP, editor. Vagbhata's Astanga Hrdayam, Varanasi: Chaukhambha Sanskrit Series Office 2002. 
14. Sahasrayogam. (A traditional compilation of Ayurvedic formulations practived by Ayurvedic physicians in Kerala). Alappuzha: Vidyarambam Publications 2016.

15. Pinar Kuru. Tamarindus indica and its health related effects. Asian Pacific Journal of Tropical Biomedicine 2014;4(9):676681.

16. Astangasamgraha. Varanasi: Chaukhambha Orientalia 1998.

17. Lalithamma K. Pharmacopeia. Trivandrum: Govt Ayurveda College Publication dept.

18. Sahu R, Dhongade HJ, Pandey A, Medicinal properties of Nardostachys jatamansi (A Review). Orient J Chem 2016;32(2): 859-866.

19. Saleh-e-In MM, Sultana N, Rahim MM. Chemical composition and pharmacological significance of Anethum Sowa L. Root. BMC Complement Altern Med 17, 127 (2017) https:// doi:10.1186/s12906-017-1601-y.

20. https://www.nutritionvalue.org/Nuts \%2C_raw\%2C_coconut_meat_nutritional_value.html.

21. McGee, Harold. On Food and Cooking: The Science and Lore of the Kitchen. New York: Scribner 2004.

22. Rao AS, Reddy SG, Babu PP, Reddy AR. The antioxidant and antiproliferative activities of methanolic extracts from Njavara rice bran. BMC Complement Altern Med 2010 Jan 28; 10:4. Published 2010 Jan 28. doi:10.1186/1472-6882-10-4.

23. Shalini V, Jayalekshmi A, Helen A. Mechanism of anti-inflammatory effect of tricin, a flavanoid isolated from Njavara rice bran in LPS induced hPBMCs and carrageenan induced rats. Mol Immnunol 2015 Aug;66(2)229-39.

24. Do Kyung Kim and Won Hah Park. Compared to male patients, females reporeted significantly less extensor muscle strength and less improvement 1 year after reconstruction. J Phys Ther Sci 2015 Dec;27 (12): 3847-3849.

25. Richard F Loesser. Ageing changes in the musculoskeletal systems contribute to develop of OA by making the joint more succeptible to joint injuries. Age related changes in musculoskeletal system and developing of osteoarthritis. Clin Geraitric Med 2010 Aug;26(3): 371-386.

26. Zheng H, et al. Body mass index and risk of knee osteoarthritis: systematic review and meta-analysis of prospective studies. BMJ Open 2015 Dec 11; 5 (12): e007568. Doi: 10.1136/ bmjopen-2014-007568.

27. Padulo J, Oliva F, Frizziero A, Maffulli N. Muscles, Ligaments and Tendons Journal - Basic principles and recommendations in clinical and field Science Research: 2018 update. MLTJ 2018; 8(3): $305-307$. 